\title{
The effect of repeated trials on a figural aftereffect*
}

\author{
HUGH WAGNER \\ Manchester University, Manchester, M13 9PL, England
}

An experiment was carried out to investigate the effect on the size of a figural aftereffect of repeated observations of the figural aftereffect figure. It was shown that a significant decrease occurred over 260 trials. The effect of practice on this distortion is thus similar to its effect on illusions. It is pointed out that a theory which explains figural aftereffects or illusions, or both, in terms of a simple physiological process cannot handle these data.

It has repeatedly been shown that if one makes a large number of observations of the size of an illusion, the illusion gradually disappears, and can even be made to occur in a direction opposite to that of the original illusion (see, e.g., Judd, 1902, 1905; Judd \& Courten, 1905; Cameron \& Steele, 1905; Kohler \& Fishback, 1950a, 1950b). This effect is obtained even when the $S$ has no knowledge of the results of the measurements and can see no difference between the situations at the beginning and at the end of the experiment. These facts have always provided a difficulty for theories of illusions.

The experiment to be reported here was prompted by the attempt of Ganz (1966) to explain most of the common illusions, and also figural aftereffects (FAEs), with the same physiological mechanism, namely lateral inhibition. FAEs are distortions produced in one figure (the test figure) by an adjacent figure (the inducing figure) that has been presented and removed before the presentation of the test figure. This is in contrast with the illusions in which the inducing and test figures are simultaneously present in the visual field. The application of Ganz's theory to the illusions has been criticized by Wagner (1968). There it was pointed out that the simple physiological mechanism proposed by Ganz was incompatible with the effect of repeated trials on the illusions.

If the theory is to be applicable even to FAEs, they should not show the practice effect that is characteristic of the illusions. The same reasons apply to this case as to the illusions, and are considered further in the Discussion section of this paper. There is little evidence that can be brought to bear on this matter. Kohler and Wallach (1944) and other workers

*This work was carried out at University College of South Wales and Monmouthshire Candiff, while the writer held a Social Science Research Council studentship. The experiment reported formed part of a thesis for the degree of $\mathrm{PhD}$ in the University of Wales. recognized the need for long rest periods during themeasurement of FAEs, since they found that the effects were cumulative if measured in rapid succession. These observations, however, cannot be contrasted with the illusion findings, since any residual process proposed as the basis of FAEs would be expected to accumulate with massed trials, and there is no comparable process whose effects could accumulate in the instantaneous illusions. There are no reports in the literature of the type of evidence that could be compared with the illusion findings, namely the effect on the size of an FAE of repeated but not massed trials. The experimental procedures of a number of workers do, however, involve such measurements, yet none has reported any overall decrement in the size of the FAE with increasing number of trials. Wilson (1965), e.g., reported an experiment which involved two Ss making up to eight runs through a series of $40 \mathrm{FAE}$ figures in a day, over a period of 2 months. He tested for the accumulation of effects within runs, but found no significant increase. He did not report that there was any progressive change in the size of the effects over the 2-month period.

Day (1962) has examined the conditions under which the decrement occurs in the Müller-Lyer illusion. The earlier workers cited above had generally allowed Ss to inspect the figures freely. Eysenck and Slater (1958) had Ss fixate a single point on the figure, but found no overall decrement in their group of Ss. Day's work confirmed this, although he found that the decrement did occur with fixation when he used small figures (subtending a visual angle of $6 \mathrm{deg} 18 \mathrm{~min}$ ), but that it occurred only with free inspection with large figures ( $20 \mathrm{deg} 36 \mathrm{~min}$ ). He concluded that for the decrement to occur it was necessary for $S s$ to be able to compare the relatively distorted parts of the figure. In large figures, this compariscn can only take place with free inspection. In small enough figures, on the other hand, the comparison can be made even with fixation of a single point. In further support of this, Day found that decrement in such small figures occurred with fixation on the central point of the figure but not with eccentric fixation. Apparently decrement with fixation occurs only when the parts of the illusion figure that are distorted relative to one another fall within the area of clear vision and so can be compared with one another. The importance of these considerations is that for the displacement type of FAE, with which we are here concerned, fixation of a single point seems to be essential for the distortion to be produced (see, e.g., Summerfield \& Miller, 1955).

The present experiment set out to investigate the effects of repeated trials on the distortion produced in a FAE. It is to be expected that if Ganz's theory is applicable to the FAE no change would occur in the size of the distortion. The FAE figure used was one that satisfied the conditions discovered by Day (1962) to be necessary for the decrement to occur in the Müller-Lyer illusion, namely, it could be considered a "small" figure (maximum vertical extent, $3 \mathrm{deg} 50 \mathrm{~min}$ ) whose comparison could be made while maintaining a single fixation. The comparison to be made with this figure was one of vernier alignment.

To be certain that the particular conditions of illumination, apparatus, and experimental procedures that obtained in this experiment would produce a decrement in the distortion of a simultaneous illusion figure, the effect of repeated trials on the Ponzo illusion was also investigated. This illusion was chosen because the necessary stimulus figures had already been prepared for another purpose. This figure could also be considered, in Day's terms, a "small" figure, since the parts to be compared were contained within a horizontal extent of $2 \mathrm{deg}$ $46 \mathrm{~min}$.

\section{Apparatus and Stimuli}

Stimuli were presented to Ss in an apparatus that was essentially a tachistoscope that was constructed by the writer. This illuminated from behind two separate stimulus figures and superimposed them in the S's view by means of a sheet of neutral density acrylic material. The apparatus was enclosed in a lightproof, wooden box. Ss viewed through a hole in the side of the box, using a cushioned chinrest and face mask.

The stimulus figure for the FAE is shown in Fig. 1. The 11/2-in--square (2 deg of visual angle) inducing figure was cut in a piece of black card and was stuck to a sheet of glass, so that 


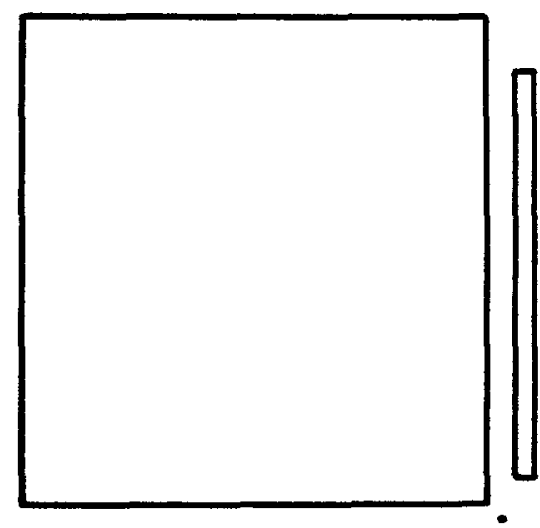

Fig. 1. The display used to measure the FAE.

light was transmitted only through the square. A pinprick in the card provided a fixation point $0.06 \mathrm{in}$. ( $5 \mathrm{~min}$ ) below and $0.04 \mathrm{in}$. ( $3 \mathrm{~min}$ ) to the right of the bottom right-hand corner of the square. The test figure was a vertical slit $1 / 16$ in. (5 min) wide and $1 \frac{1 / 4}{\mathrm{in}}$. ( $1 \mathrm{deg} 40 \mathrm{~min}$ ) long, cut in black card. This was stuck to a glass sheet covering only its upper half. A pinprick provided a fixation point $0.12 \mathrm{in}$. (10 $\mathrm{min})$ below and $0.04 \mathrm{in}$. $(3 \mathrm{~min})$ to the left of the bottom left-hand corner of the slit. The two glass sheets slid into the apparatus in front of the two light sources so that the fixation points were superimposed to the S's view. A comparison figure identical in shape to the test figure was cut in black card and was fixed to a sheet of clear acrylic material, so that it covered its lower half. This slid into the apparatus behind the test figure so that the two pieces of black card overlapped by $1 / 8$ in. The comparison figure was adjustable horizontally by means of a rack and worm gear device, operated by the $S$ through a chain drive connected to a knob at the S's left hand.

The stimulus figures for the Ponzo illusion were similarly cut in black card, and provided two 1/8-in. $(10 \mathrm{~min})$ slits converging to the left of the S's visual field, forming an angle of $28 \mathrm{deg}$ with each other. Two vertical slits, 0.04 in. ( $3 \mathrm{~min}$ of arc) wide and 2 in. ( $2 \mathrm{deg} 40 \mathrm{~min}$ ) apart were positioned between the converging lines. The left-hand line was $1 \frac{1 / 2}{\mathrm{in}}$. ( $2 \mathrm{deg}$ ) long, and the right-hand one could be varied in length between 1 in. ( $1 \mathrm{deg} 20 \mathrm{~min}$ ) and $2 \frac{1 / 2}{\mathrm{in}}$. (3 deg $20 \mathrm{~min}$ ) by means of the rack and worm device. Pinpricks provided a fixation point midway between the vertical slits.

Illumination was provided by two square arrays of nine $12-\mathrm{V}$ pilot lamp bulbs, diffused by cartridge paper. Each provided a 101/2-in.-square (13 deg $15 \mathrm{~min}$ ) field. The effective viewing distance was 43 in. The figure-ground contrast was greater than $300: 1$, with figure luminance $10.85 \mathrm{~cd} / \mathrm{m}^{2}$. Readings of the position or length of the comparison figures were made by means of a vernier scale attached to the acrylic stimulus sheets and to the box; they were accurate to 0.005 in (0.4 min of arc).

\section{Subjects}

The Ss were three technicians and two research students from the Department of Psychology at University College, Cardiff. None was aware of the purpose of the experiment or of the effect of practice on the illusions. All claimed normal eyesight.

\section{Design}

Three Ss were allocated to the FAE condition and two to the Ponzo illusion condition. Each $\mathbf{S}$ attended two sessions each day, one in the morning and one in the afternoon, for 13 weekdays. Days 5 and 6 were separated by a weekend, as were Days 10 and 11. Ss for the FAE made 10 adjustments of the comparison figure after previous fixations of the inducing figure and 20 adjustments without previous fixations in each session, a total of 260 experimental and 520 control adjustments. Ss for the Ponzo illusion made 20 adjustments of the whole figure and 20 of the two vertical slits alone in each session, a total of 520 experimental and 520 control adjustments. This made the lengths of the sessions approximately equal for the members of the two groups.

\section{Procedure}

Ss were instructed in the task, which was for the FAE to adjust the lower slit to appear in line with the upper one, and for the illusion to adjust the length of the right-hand line to appear equal to the left-hand one. In both cases, Ss were instructed to maintain fixation on the fixation point. The starting position was varied by moving the adjustable figure left, right, right, left, left, and so on, for the FAE, and alternately left and right for the illusion. The size of this movement was varied from trial to trial to avoid a motor learning effect. For the FAE, one experimental adjustment alternated with two control adjustments; for the illusion, experimental and control adjustments were alternated. Ss were reminded before each trial to maintain fixation. The time taken to make each experimental adjustment was measured with a stopwatch and recorded to the nearest second. For the FAE, Ss fixated the inducing figure for $30 \mathrm{sec}$ before it was replaced by the test and comparison figures.

\section{RESULTS}

The mean distortions for each $\mathbf{S}$ for the first and second half of each session were calculated by subtracting the mean control from the mean experimental readings. The mean scores for each day for all Ss were also calculated, and are shown in Figs. 2 and 3. Figure 2 shows that the expected decrement in the Ponzo illusion indeed occurred, the distortion decreasing from a mean of 0.15 in. on Day 1 to below 0.05 in. on the last 6 days. Since the main concern of this report is the FAE, these data will not be considered further.

Figure 3 shows a much less regular decrease in the size of the FAE, and these data were subjected ${ }^{1}$ to an analysis of variance for trends, as described by Alexander (1946). This analysis showed a significant overall slope in these data $(F=15.81$, df $=1 / 100, p<.01)$. Table 1 shows the individual and group data for the FAE and the adjustment times.

\section{DISCUSSION}

Before concluding that the change obtained is a real decrement in the size of the FAE, it is necessary to consider two alternative explanations. First, the obtained results could be produced by Ss making a gradual increase in the time they take to adjust the figures at the end of the fixation period. Since the FAE decays rapidly (Hammer, 1949), such an increase would have the effect of lowering the measurements made of the FAE. That this increase should occur seems extremely unlikely, and the data presented in Table 1 show that, as might be expected, there was an overall decrease in adjustment time. Furthermore, the individual data show that the decrease is most obvious for the two Ss showing the clearest decrement in the FAE. Since adjustments were being made, by two Ss, more quickly at the end of the experiment than at the beginning, so that measurement was obtained at an earlier stage of the decay process, the obtained decrement in the FAE becomes even more striking.

The other possible alternative 


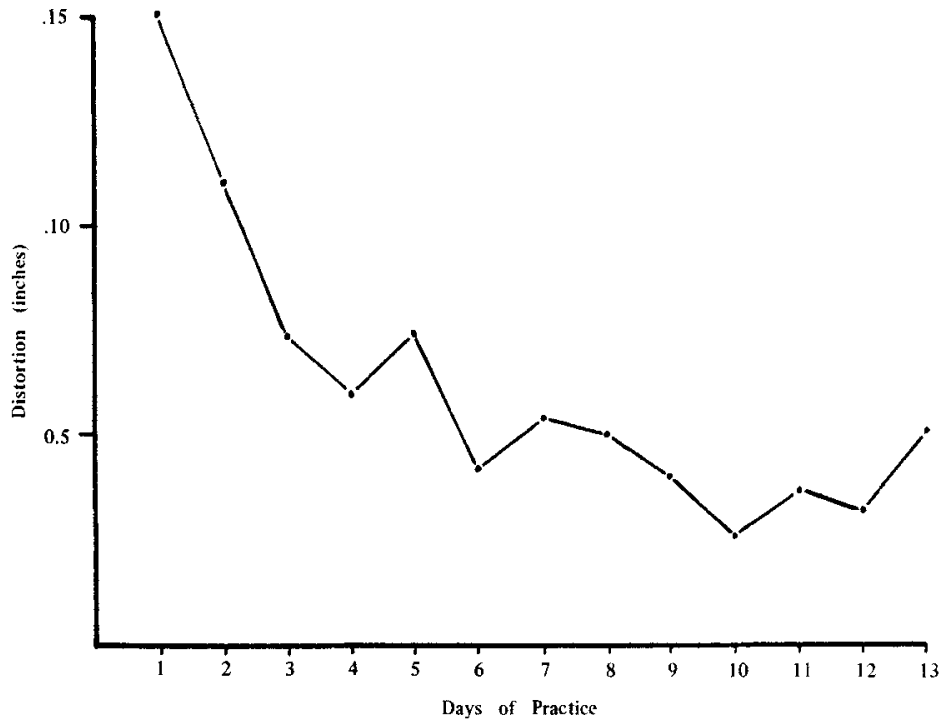

Fig. 2. The effect of practice on the distortion in the Ponzo illusion. The data plotted are the daily average apparent differences, for two Ss, in the length of the bars in the Ponzo figure.

explanation is that the FAE may be cumulative. If it is cumulative, it could come to have as much effect on the control measurements as on the experimental ones. The apparent decrement in the FAE would then be caused not be a real decrement (represented here by a decrease in the experimental measurements) but by an increase in the control measurements, caused by the persistence of the FAE. There are two reasons why this cannot

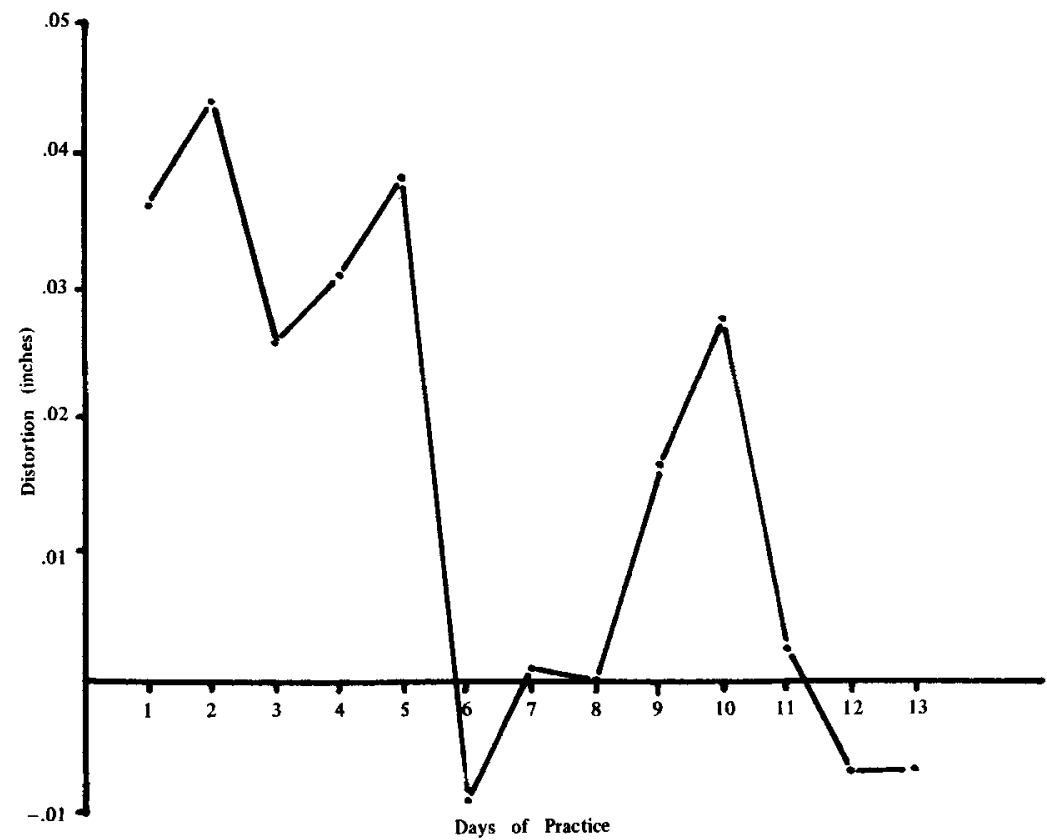

Fig. 3. The effect of practice on the FAE. The data plotted are the daily average displacements, for three $S s$, of the upper line in Fig. 1. Positive distortion indicates displacement away from the square. which were separated by weekends, just when the supposed persistence of the FAE onto the control measurements would be expected to decay most. Similar accelerated decrements over days of nonpractice were found with illusion figures by Judd (1902) and by Lewis (1908). The data indicate that there may be a buildup of distortion within and between sessions which prevents, or even reverses, the overall trend, but which is dissipated over the two weekends. (2) Table 2 shows that the overall tendency is for the control measures to decrease, one individual showing this decrease very markedly, and neither of the other two showing any tendency to increase. This tendency and the fact that there are high correlations between the experimental and the control readings can be considered to be similar to the time trends found by Brown (1953) in his measurements of half-meridional differences. Brown attributed these trends to an unstable factor in the visual system, but could reach no firm conclusion about either the nature of this factor or of what caused it to change. Large day-to-day variations in points of subjective equality are, of course, well known, and in this instance the correlations observed, while reflecting this overall variability, do not affect the finding of a decrement in the FAE.

It can, then, be concluded that the results indicate a real decrement in the FAE with repeated trials. This finding is considered to be incompatible with any theory of FAEs that is based on a simple physiological mechanism. In Ganz's (1966) theory, e.g., the effects are said to be due to the action of lateral inhibition from the inducing figure in shifting the distribution of excitation produced by the test figure away from the position of the inducing figure. The decrement of the effect with repeated trials would seem to demand that this lateral inhibition between the parts of the figure decreases with repetition. If the FAE, like the Müller-Lyer illusion (Köhler \& Fishback, 1950a) can be shown to reverse in direction, this would further indicate that the lateral inhibition can reverse its direction of effect. There seems to be no evidence that this can occur; indeed, it is inconceivable in Ganz's formulation for lateral inhibition to do this.

Köhler \& Fishback (1950a) ascribed the decrement in the illusions to a buildup of satiation between the parts of the figures. This explanation was dismissed by Day (1962), who quoted evidence that the decrement occurs under conditions in which satiation could not build up. It is unlikely that this explanation could apply to the 
Table 1

Individual and Group Data for the FAE Distortion (D $\times 1 / 100$ in.) (Daily Averages) and for Adjustment Times of the Experimental Measures ( $T$ Sec)

\begin{tabular}{|c|c|c|c|c|c|c|c|c|c|c|}
\hline \multirow[b]{3}{*}{ Day } & \multicolumn{6}{|c|}{ Subject } & \multicolumn{4}{|c|}{ Group } \\
\hline & \multicolumn{2}{|c|}{1} & \multicolumn{2}{|c|}{2} & \multicolumn{2}{|c|}{3} & \multirow{2}{*}{$\begin{array}{c}\text { Mean } \\
\mathbf{D}\end{array}$} & \multirow{2}{*}{$\begin{array}{c}\text { SD } \\
\text { D } \\
\end{array}$} & \multirow{2}{*}{$\begin{array}{l}\mathbf{t} \\
\mathbf{D}\end{array}$} & \multirow{2}{*}{$\begin{array}{c}\text { Mean } \\
T\end{array}$} \\
\hline & D & $\mathbf{T}$ & D & $\mathbf{T}$ & D & $\mathbf{T}$ & & & & \\
\hline $\begin{array}{l}1 \\
2 \\
3 \\
4 \\
5\end{array}$ & $\begin{array}{l}3.75 \\
8.25 \\
5.25 \\
4.50 \\
5.25\end{array}$ & $\begin{array}{l}4.85 \\
5.55 \\
5.25 \\
4.45 \\
3.90\end{array}$ & $\begin{array}{l}1.25 \\
0.50 \\
1.50 \\
2.00 \\
0.75\end{array}$ & $\begin{array}{l}2.50 \\
2.50 \\
2.55 \\
2.30 \\
2.75\end{array}$ & $\begin{array}{l}5.75 \\
4.50 \\
1.00 \\
3.00 \\
5.50\end{array}$ & $\begin{array}{l}2.10 \\
2.15 \\
2.50 \\
2.40 \\
2.55\end{array}$ & $\begin{array}{l}3.58 \\
4.42 \\
2.58 \\
3.17 \\
3.83\end{array}$ & $\begin{array}{l}2.25 \\
3.88 \\
2.32 \\
1.26 \\
2.67\end{array}$ & $\begin{array}{l}2.75^{*} \\
1.97^{*} \\
1.93^{*} \\
4.36 \dagger \\
2.68^{*}\end{array}$ & $\begin{array}{l}3.15 \\
3.40 \\
3.43 \\
3.05 \\
3.07\end{array}$ \\
\hline $\begin{array}{r}6 \\
7 \\
8 \\
9 \\
10\end{array}$ & $\begin{array}{r}0.25 \\
4.00 \\
-1.25 \\
1.75 \\
4.75\end{array}$ & $\begin{array}{l}4.10 \\
3.75 \\
3.55 \\
3.10 \\
3.55\end{array}$ & $\begin{array}{r}-1.00 \\
-1.25 \\
-1.25 \\
-0.75 \\
3.00\end{array}$ & $\begin{array}{l}2.80 \\
2.55 \\
2.50 \\
2.15 \\
2.40\end{array}$ & $\begin{array}{r}-2.00 \\
-2.50 \\
2.50 \\
4.00 \\
0.75\end{array}$ & $\begin{array}{l}2.25 \\
2.15 \\
1.80 \\
2.00 \\
1.85\end{array}$ & $\begin{array}{r}-0.92 \\
0.08 \\
0.00 \\
1.67 \\
2.83\end{array}$ & $\begin{array}{l}1.13 \\
3.45 \\
2.17 \\
2.38 \\
2.00\end{array}$ & $\begin{array}{c}-1.43 \\
0.17 \\
0.00 \\
0.99 \\
2.45 *\end{array}$ & $\begin{array}{l}3.05 \\
2.82 \\
2.62 \\
2.42 \\
2.60\end{array}$ \\
\hline $\begin{array}{l}11 \\
12 \\
13 \\
\end{array}$ & $\begin{array}{r}1.50 \\
0.50 \\
-1.00\end{array}$ & $\begin{array}{l}3.45 \\
3.50 \\
3.00\end{array}$ & $\begin{array}{r}0.50 \\
-2.50 \\
0.00\end{array}$ & $\begin{array}{l}2.55 \\
2.50 \\
2.25\end{array}$ & $\begin{array}{r}-1.25 \\
0.00 \\
-1.00\end{array}$ & $\begin{array}{l}1.95 \\
2.00 \\
1.85\end{array}$ & $\begin{array}{r}0.25 \\
-0.67 \\
-0.67\end{array}$ & $\begin{array}{l}1.39 \\
1.61 \\
0.58\end{array}$ & $\begin{array}{r}0.31 \\
-0.72 \\
-1.94^{*}\end{array}$ & $\begin{array}{l}2.65 \\
2.67 \\
2.37\end{array}$ \\
\hline
\end{tabular}

$*_{p}<.10,+p<.025$

FAE decrement since the distortion itself in the FAE was said to be due to satiation between the parts of the figure (Köhler \& Wallach, 1944) (in this case between the square and the upper slit). For the decrement in distortion to be due to a greater buildup of satiation in any part of the figure seems to be impossible, particularly when the distortion is measured by alignment with a comparison figure in another part of the field and not by its apparent distance from the inducing figure. Certainly, increased satiation within or around the square could not explain why the upper slit came, with repetition, to aproar nearer to the square, since the ifect of this would be, rather, to inc ease the FAE. The satiation theory, noreover, has been shown to have $d$ ubtful validity (see, e.g., Lashley et a 1951; Spitz, 1958).

A possible al irnative explanation of the decremen which is available to $a$ theory such a that of Ganz is that the decrement is due to some leaming process overcoming the physiological mechanism. Köhler and Fishback (1950a) discussed this alternative to the satiation theory and rejected it for a number of reasons: (1) the decrements occur when the $S$ is unaware of any distortion and when he can see no difference between the figures at the beginning and at the end of the experiment; (2) for the illusion figures, there is a lot of evidence to show that not only can the illusory effects be made to decrease or disappear, but they can even be made to reverse their direction (see, e.g., Judd, 1902; Judd \& Courten, 1905; Cameron \& Steele, 1905; Köhler \& Fishback, 1950a, 1950b; (3) it has been shown that when the distortion in a particular illusion has been made to disappear, changing the orientation of the figure or the position from which it is viewed causes the distortion to reappear (Judd \& Courten, 1905; Köhler \& Fishback, 1950a). Eysenck and Slater (1958) have argued that if the connotation of the term learning is extended, the first two, at least, of these objections can be overcome. Ss,

Table 2

Individual and Group Experimental (E) and Control (C) Readings for the FAE (Daily Means $X 1 / 100$ in. Measured from Arbitrary Scale $Z$ ero)

\begin{tabular}{|c|c|c|c|c|c|c|c|c|}
\hline \multirow[b]{2}{*}{ Day } & \multicolumn{2}{|c|}{ S 1} & \multicolumn{2}{|c|}{52} & \multicolumn{2}{|c|}{ S 3} & \multicolumn{2}{|c|}{ Group } \\
\hline & $\mathbf{E}$ & C & $\mathbf{E}$ & $\mathbf{C}$ & $\mathbf{E}$ & C & Mean E & Mean C \\
\hline $\begin{array}{l}1 \\
2 \\
3 \\
4 \\
5\end{array}$ & $\begin{array}{l}176.25 \\
182.00 \\
177.50 \\
185.50 \\
185.00\end{array}$ & $\begin{array}{l}172.50 \\
173.75 \\
172.25 \\
181.00 \\
179.75\end{array}$ & $\begin{array}{l}179.00 \\
182.25 \\
179.25 \\
184.75 \\
184.25\end{array}$ & $\begin{array}{l}177.75 \\
181.75 \\
177.75 \\
182.75 \\
183.50\end{array}$ & $\begin{array}{l}181.25 \\
180.75 \\
175.50 \\
178.50 \\
179.00\end{array}$ & $\begin{array}{l}175.50 \\
176.25 \\
174.50 \\
175.50 \\
173.50\end{array}$ & $\begin{array}{l}178.83 \\
181.67 \\
177.41 \\
182.91 \\
182.75\end{array}$ & $\begin{array}{l}175.25 \\
177.25 \\
174.83 \\
179.75 \\
178.91\end{array}$ \\
\hline $\begin{array}{r}6 \\
7 \\
8 \\
9 \\
10\end{array}$ & $\begin{array}{l}185.00 \\
177.75 \\
174.25 \\
176.00 \\
177.50\end{array}$ & $\begin{array}{r}184.75 \\
173.75 \\
175.50 \\
.74 .25 \\
\mathbf{7 2 . 7 5}\end{array}$ & $\begin{array}{l}187.25 \\
183.75 \\
177.25 \\
180.25 \\
183.25\end{array}$ & $\begin{array}{l}188.25 \\
185.00 \\
178.50 \\
181.00 \\
179.75\end{array}$ & $\begin{array}{l}164.50 \\
166.50 \\
162.75 \\
168.75 \\
168.00\end{array}$ & $\begin{array}{l}166.50 \\
168.50 \\
160.25 \\
164.75 \\
167.25\end{array}$ & $\begin{array}{l}178.91 \\
176.00 \\
171.41 \\
175.00 \\
176.25\end{array}$ & $\begin{array}{l}179.83 \\
175.75 \\
171.41 \\
173.33 \\
173.25\end{array}$ \\
\hline $\begin{array}{l}11 \\
12 \\
13\end{array}$ & $\begin{array}{l}172.00 \\
175.00 \\
174.00\end{array}$ & $\begin{array}{l}171.00 \\
174.50 \\
175.00\end{array}$ & $\begin{array}{l}183.50 \\
175.75 \\
176.50\end{array}$ & $\begin{array}{l}183.00 \\
178.25 \\
176.50\end{array}$ & $\begin{array}{l}168.75 \\
164.25 \\
164.50\end{array}$ & $\begin{array}{l}170.00 \\
164.25 \\
165.50\end{array}$ & $\begin{array}{l}174.75 \\
171.67 \\
171.67\end{array}$ & $\begin{array}{l}174.67 \\
172.33 \\
172.33\end{array}$ \\
\hline
\end{tabular}

they say, frequently become discontented with the setting they have made while it is being noted. On the next trial there will be a tendency to make the setting further in the direction corresponding to the "discontent." This could set up a trend in a series of measurements. This hypothesis does have the advantage that it makes possible the interpretation of individuals whose trend with repeated trials is an increase or who show no trend at all; such individuals have been frequently reported. However, it does depend on the "discontent" being felt in the same direction on successive trials, and it seems intuitively to be more likely that the direction of discontent should alternate from trial to trial, as the tendency to make the next setting further in one direction should then produce discontent in the opposite direction. Furthermore, as Eysenck and Slater themselves note, this hypothesis gives no reason to suppose that the trend should occur more often as a decrement than as an increment, which is undoubtedly the case.

The third of Köhler and Fishback's reasons can be validly criticized. They seem to have overstated the case for the effect of changing the orientation of the figure; they cite Judd and Lewis as providing evidence that on rotating the Müller-Lyer figure through $90 \mathrm{deg}$, the illusion reappears, but there is no reference to such observations in the works cited. Rather, these authors refer to reversal of the figures and stress that this procedure produces evidence of a transfer of training in that fewer trials are needed for the distortion to disappear (Judd, 1905; Lewis, 1908).

Day (1962) concluded from his investigations that the decrement was a learning effect. He did not consider 
Köhler and Fishback's arguments but, as pointed out above, produced evidence against their own satiation explanation. Day's conclusion was that the perceptual learning that is the basis of the decrement was dependent upon conditions which permitted the $S$ to compare one element of the figure with the other and was an example of the well-established phenomenon of discrimination training. This does not overcome the first two of Köhler and Fishback's (1950a) objections to an interpretation in terms of learning, and it cannot account for the fact that Day (1962) himself stresses, namely that the decrement is not universal, and for some individuals an increment in the distortion occurs.

These considerations apply with equal strength to the FAE. Unless the proponents of the learning explanation can obtain concrete evidence that the decrements to the illusions and to the FAE are due to learning processes rather than to changes in the processes causing the distortion or can refute Köhler and Fishback's arguments, it is difficult to see how a simple physiological theory such as the peripheral one of Ganz or the central one of Köhler and his associates can explain these phenomena.
REFERENCES

ALEXANDER, H. W. A general test for trend. Psychological Bulletin, 1946, 43, 533-557.

BROWN, K. T, Factors affecting differences in apparent size between opposite halves of a visual meridian. Journal of the Optical Society of America, 1953, 43, 464-472.

CAMERON, E. H., \& STEELE, W. M. The Poggendorf illusion. Psychological Review Monograph Supplement, 1905, 7 , 83-111.

DAY, R. H. The effects of repeated trials and prolonged fixation on error in the Müller-Lyer figure. Psychological Monographs, 1962, 76(14, Whole No. 533).

EYSENCK, H. J.. \& SLATER, P. Effects of practice and rest on fluctuations in the Müller-Lyer illusion. British Journal of Psychology, 1958, 49, 246-256.

GANZ. L. Mechanism of the figural aftereffects. Psychological Review, 1966 , 73, $128-150$.

HAMMER, E. R. Temporal factors in figural after-effects. American Journal of Psychology, 1949, 62, 337-354.

JUDD, C. H. Practice and its effects on the perception of illusions. Psychological Review, 1902, 9, 27-39.

JUDD, C. H. The Muller-Lyer illusion. Psychological Review Monograph Supplement, 1905, 7, 55-81.

JUDD, C. H., \& COURTEN, H. C. The Zölliner illusion. Psychological Review Monograph Supplement, 1905, 7 , 112-139.

KÖHLER, W. \& FISHBACK, J. The destruction of the Muiller-Lyer illusion in repeated trials: (1) An exanuination of two theories. Journal of Experimental
Psychology, 1950a, 40, 267-281.

KÖHLER, W. \& FISHBACK, J, The destruction of the Müller-Lyer illusion in repeated trials: (2) Satiation patterns and memory traces. Journal of Experimen ${ }^{4} 1$ Psychology, 1950b, 40, 398-410.

KÖHLER, W., \& WALLACH, H. Figural aftereffects. Proceedings of the American Philosophical Society, 1944, 88, 269-357.

LASHLEY, K. S., CHOW, K. L., \& SEMMES, J. An examination of the electrical field theory of cerebral integration. Psychological Review, 1951 , 58, 123-136.

LEWIS, E. O. The effect of practice on the Muillex-Lyer illusion. British Journal of Psychology, 1908, 2, 294-306.

SPITZ, H. H. The present status of the Kohler-Wallach theory of satiation. Psychological Bulletin, 1958, 55, 1-28.

SUMMERFIELD, A., \& MLLER, K, $M$, Visual illusion and figural after-effect, with and without fixation. Quarterly Journal of Experimental Psychology, $1955,7,149-158$.

WAGNER, H. L. The illusions and Ganz's theory of contour displacements. British Journal of Psychology, 1968, 59, 361-367.

WILSON, J. W. Adaptation and repulsion in the figural after-effect. Quarteriy Joumal of Experimental Psychology, 1965, 17, 1-13.

NOTE

1. I would like to thank Geoffrey Barrett for writing and running the computer program for this analysis.

(Accepted for publication February 17, 1971.) 